\title{
BMJ Open Risk for metabolic diseases in normal weight individuals with visceral fat accumulation: a cross-sectional study in Japan
}

Yukako Tatsumi, ${ }^{1,2}$ Yoko M Nakao, ${ }^{2,3}$ Izuru Masuda, ${ }^{4}$ Aya Higashiyama, ${ }^{2}$ Misa Takegami, ${ }^{2}$ Kunihiro Nishimura, ${ }^{2}$ Makoto Watanabe, ${ }^{3}$ Takayoshi Ohkubo, ${ }^{1}$ Tomonori Okamura, ${ }^{5}$ Yoshihiro Miyamoto ${ }^{2,3}$

To cite: Tatsumi $Y$, Nakao YM, Masuda I, et al. Risk for metabolic diseases in normal weight individuals with visceral fat accumulation: a crosssectional study in Japan. BMJ Open 2017;7:e013831. doi:10.1136/bmjopen-2016013831

- Prepublication history and additional material is available. To view please visit the journal (http://dx.doi.org/ 10.1136/bmjopen-2016013831).

Received 10 August 2016 Revised 15 November 2016 Accepted 24 November 2016

CrossMark

For numbered affiliations see end of article.

Correspondence to

Yukako Tatsumi;

y.tatsumi@med.teikyo-u.ac.jp

\section{ABSTRACT}

Objective: To investigate the association between visceral fat area (VFA) and metabolic syndrome (Mets) among normal weight Japanese.

Design: A cross-sectional study.

Setting: The health check-up centre of the Takeda Hospital group in Kyoto, Japan.

Methods: This study involved 1674 men and 1448 women aged 30-74 years who underwent medical check-ups in 2012 in the health check-up centre. They were stratified by Body Mass Index (BMI cut-off for obesity is set at $23.0 \mathrm{~kg} / \mathrm{m}^{2}$ for Asians): normal weight $18.5-22.9 \mathrm{~kg} / \mathrm{m}^{2}$ or higher weight $\geq 23.0 \mathrm{~kg} / \mathrm{m}^{2}$. The age-adjusted ORs of the 2nd to 4th groups of sexspecific VFA quartiles compared with the 1st quartile for a Mets component clustering were estimated. The clustering was having two or more of the following factors: high blood pressure, high fasting blood glucose (FBG), low high-density lipoprotein cholesterol (HDL-C) and high triglycerides. Statistical analyses were conducted in 2016.

Results: Participants in the 2nd to 4th VFA quartiles had significantly higher clustering risks; ORs were 3.4 (1.5 to 8.0), 6.3 (2.8 to 14.2) and 9.3 (4.2 to 20.7) for normal weight participants, and 1.7 (1.2 to 2.6), 2.6 (1.8 to 3.9) and 6.0 (4.1 to 8.8) for higher weight participants, respectively. The ORs of the 4th VFA quartile for Mets components were significantly higher; ORs for normal weight participants were 2.1 (1.5 to 3.0) (high blood pressure), 2.4 (1.4 to 4.2) (high FBG), 5.2 (2.1 to 12.9) (low HDL-C) and 12.0 (5.7 to 25.3) (high triglycerides), and higher weight participants were 3.9 (2.8 to 5.5 ), 4.1 (2.8 to 6.2 ), 3.9 (2.2 to 6.9 ) and 5.0 (3.4 to 7.4 ), respectively.

Conclusions: Among participants with normal weight, as well as those of higher weight, dose-dependent responses were observed between VFA and risk for Mets components and the clustering among Japanese adults. VFA may be useful information for interventions to improve metabolic risk factors in people with normal weight.

\section{Strengths and limitation of this study}

- This is the first study highlighting the associations between visceral fat area and metabolic syndrome among normal weight Asians (Body Mass Index $18.5-22.9 \mathrm{~kg} / \mathrm{m}^{2}$ ).

- There is the potential for a selection bias as this study involved the participants with relatively high health awareness who voluntarily underwent comprehensive medical check-ups.

- There are potential limitations for a crosssectional design which could not clarify causal associations.

\section{INTRODUCTION}

Obesity, characterised as excessive body fat, is a risk factor for metabolic and cardiovascular diseases. For the purposes of preventing and predicting these diseases, anthropometric measurements are used as screening for obesity at health check-ups. Of several anthropometric measurements, Body Mass Index (BMI) is used to assess generalised obesity because it correlates highly with the percentage of body fat. ${ }^{1}$ Cut-off points for BMI are defined by the WHO; a BMI of $18.5-24.9 \mathrm{~kg} / \mathrm{m}^{2}$ is considered normal weight. ${ }^{2}$ For Asians, the WHO decreased the upper cut-off point to a BMI of $23.0 \mathrm{~kg} / \mathrm{m}^{2}$ because Asians have higher percentages of body fat for the same age, sex and BMI compared with Caucasians and have a higher prevalence of metabolic diseases among those even below a BMI of $25.0 \mathrm{~kg} / \mathrm{m}^{2}$. However, it is undeniable that fat accumulation is associated with metabolic and cardiovascular diseases even among normal weight individuals with BMIs $18.5-22.9 \mathrm{~kg} / \mathrm{m}^{2}$ 
because BMI is related to fat-free mass and does not directly represent fat accumulation. ${ }^{1}$

In recent years, attention has been given to reports that people who have normal weight defined by BMI but high levels of body fat or a high waist-to-hip ratio, normal weight central obesity, also have high risk for metabolic and cardiovascular diseases. ${ }^{3}{ }^{4}$ These reports may indicate that body fat accumulation especially in the abdominal area is a key component for these diseases among normal weight people. In studies measuring the abdominal fat area, ${ }^{5-18}$ some studies investigated the associations between the visceral fat area (VFA) and metabolic syndrome (Mets) components among normal weight people with a $\mathrm{BMI}<25.0 \mathrm{~kg} / \mathrm{m}^{2} .{ }^{7} 81213$ However, although the association between VFA and lipid profile has been investigated, the associations with blood pressure (BP), blood glucose and Mets component clustering have not yet been investigated among normal weight Asians as defined by the WHO (BMI 18.5-22.9 $\mathrm{kg} / \mathrm{m}^{2}$ ). ${ }^{7} 12$

Therefore, we investigated the risk of high VFA for Mets components and the clustering of these components in Japanese adults with BMIs $18.5-22.9 \mathrm{~kg} / \mathrm{m}^{2}$ to clarify whether visceral fat accumulation is associated with Mets. If there is a significant association, VFA may be useful information to find targets to improve Mets among normal weight individuals.

\section{RESEARCH DESIGN AND METHODS Study participants}

The present cross-sectional study included 3622 individuals who underwent a comprehensive medical check-up at Takeda Hospital Group in 2012. Of these, 500 were excluded for the following reasons: (1) age $<30$ or $>75$ years $(\mathrm{n}=165),(2)$ BMI $<18.5 \mathrm{~kg} / \mathrm{m}^{2} \quad(\mathrm{n}=246)$ and (3) missing data $(\mathrm{n}=79)$. The remaining 3122 participants were included in the analysis (figure 1). Written informed consent was obtained from all participants prior to the start of the study.

\section{Data collection}

Participants completed a questionnaire involving demographic information, medical history, smoking (current, quit or never) and drinking habits (current, quit or never), exercise habits (with frequency and time) and eating behaviours. Participants were measured for height and weight with light clothing. BMI was calculated as weight $(\mathrm{kg})$ divided by height squared $\left(\mathrm{m}^{2}\right)$. VFA was measured in the morning before breakfast by dual bioelectrical impedance analysis which is the first device in the world for measuring visceral fat without X-ray exposure (DUALSCAN; Omron Healthcare Co., Kyoto, Japan). ${ }^{19-21}$ BP was measured using a sphygmomanometer after $5 \mathrm{~min}$ of rest. Blood tests were conducted in the morning following an overnight fast. All measurements were carried out in the clinical laboratory of the Takeda Hospital Group. Blood glucose, high-density

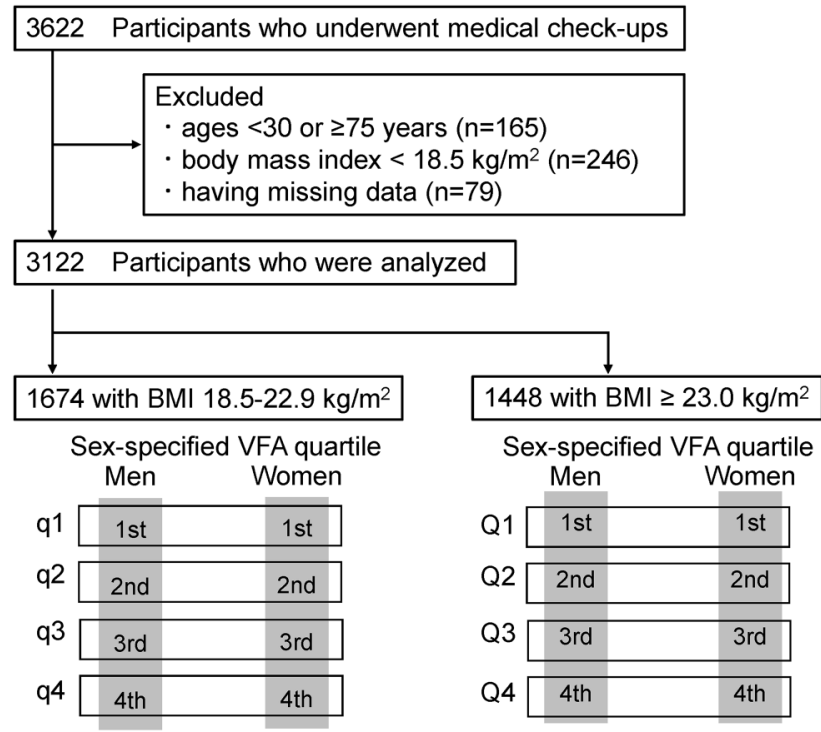

Figure 1 Selection and categorisation of participants.

lipoprotein cholesterol (HDL-C) and triglyceride (TG) concentrations were measured by enzymatic methods.

\section{Outcome definitions}

The Mets components used as outcomes in the present study were high BP, high fasting blood glucose (FBG), low HDL-C and high TG. High BP was defined as systolic $\mathrm{BP} \geq 130 \mathrm{~mm} \mathrm{Hg}$ and/or diastolic $\mathrm{BP} \geq 85 \mathrm{~mm} \mathrm{Hg}$ and/or the use of antihypertensive agents. High FBG was defined as $\mathrm{FBG} \geq 5.55 \mathrm{mmol} / \mathrm{L}$ and/or use of antidiabetic agents. Low HDL-C was defined as HDL-C $<1.29 \mathrm{mmol} / \mathrm{L}$ (women) or $1.03 \mathrm{mmol} / \mathrm{L}$ (men). High TGs were defined as TGs $\geq 1.69 \mathrm{mmol} / \mathrm{L}$. These definitions were based on the uniform definition proposed in the 2009 joint international statement. ${ }^{22}$ Furthermore, Mets component clustering was defined as having two or more of the above four Mets components.

\section{Statistical analysis}

Sex-specific analyses were performed because VFA distributions differ by sex. Sex differences in characteristics were defined by Student's t-test for normally distributed continuous variables, Mann-Whitney $\mathrm{U}$ test for skewed continuous variables, and $\chi^{2}$ test for categorical and dichotomous variables. The normality of continuous variables was determined by the one-sample Kolmogorov-Smirnov test. Although all continuous variables were normally distributed $(\mathrm{p}<0.001$ in all variables), TGs were analysed using the Mann-Whitney U test because TG data visually had a log-normal distribution.

Participants were stratified into two BMI groups by the WHO Asian specific criteria: a normal weight group (BMI $18.5-22.9 \mathrm{~kg} / \mathrm{m}^{2}$ ) and a higher weight group $\left(\mathrm{BMI} \geq 23.0 \mathrm{~kg} / \mathrm{m}^{2}\right){ }^{2}{ }^{23}$ Participants were further classified using VFA quartiles by sex and BMI strata (normal weight: q1, q2, q3 and q4; higher weight: Q1, Q2, Q3 
and Q4) (figure 1). Percentages of participants having Mets components according to BMI strata and VFA quartiles were calculated. Logistic regression analysis was used to estimate age-adjusted ORs and 95\% CIs for each Mets component and the clustering among participants in the 2nd, 3rd and 4th quartiles as compared with the 1st quartile by BMI strata. The same analyses were conducted among participants without liver or renal disease, thyroid disease, tumours or psychiatric diseases to confirm the associations and to eliminate the potential bias caused by these diseases. Furthermore, stratifying by age (30-64 years or 65-74 years) and BMI $\left(18.5-22.9 \mathrm{~kg} / \mathrm{m}^{2}\right.$ or $\left.\geq 23.0 \mathrm{~kg} / \mathrm{m}^{2}\right)$, participants were recategorised according to sex-specific VFA quartiles and ORs were estimated. Interactions between age and VFA for Mets component clustering in each BMI strata were tested.

Finally, to clarify the association between improvable lifestyle factors and VFA among normal weight, the differences of VFA according to lifestyle factors were assessed using analysis of covariance. The dependent variable was VFA and the independent variables were age and the following lifestyle factors: drinking habits (current, quit or never), smoking habits (current, quit or never), exercise habits $(0,1-59$ or 60 or more $\mathrm{min} /$ week), ${ }^{24}$ eating until full (yes, no) and eating quickly (yes, no). ${ }^{25}$ Owing to the small sample size of ex-drinkers (men, $n=24$; women, $n=15$ ), these participants were combined with the never drinkers. Multiple comparisons for smoking and exercise habits were conducted using the Bonferroni method. In addition, multiple stepwise regression analyses (the significance level was 0.05 for entry and 0.1 to remain) were conducted to confirm the independent factors associated with VFA. All reported $\mathrm{p}$ values were two tailed and those $<0.05$ were considered statistically significant. All data were analysed using SPSS, V.22.0J (Japan IBM, Tokyo, Japan) and Stata, V.14.1 (IBM Corp., Armonk, New York, USA) in 2016.

\section{RESULTS}

\section{Characteristics of participants}

The characteristics of participants are shown in table 1 . The mean age was 51.2 years in men and 49.8 years in women. Means of BMI, BP, TG and FBG were significantly higher in men than in women. Mean levels of HDL-C were significantly higher in women than in men. Lifestyles characteristics, except for eating until full, were different by sex. Among those with a BMI of 18.5$22.9 \mathrm{~kg} / \mathrm{m}^{2}$, there were 745 men (mean $\mathrm{BMI}=21.3 \pm 1.1$ ) and 1033 women (mean BMI=20.6 \pm 1.3 ). Of those with a $\mathrm{BMI} \geq 23.0 \mathrm{~kg} / \mathrm{m}^{2}$, there were 929 men (mean $\mathrm{BMI}=25.7$ \pm 2.5 ) and 415 women (mean BMI $=25.8 \pm 2.7$ ).

\section{VFA and Mets}

The percentages of participants having Mets components according to BMI and VFA are shown in table 2. Among men, the 25th, 50th and 75th centile values of VFA $\left(\mathrm{cm}^{2}\right)$ were $43.7,56.6$ and 71.6 in the normal weight group, and 70.7, 88.3 and 109.3 in the higher weight group. Among women, the values were 28.6, 39.1 and 50.5 in the normal weight group, and 48.1, 67.0 and 86.4 in the higher weight group. Since, some groups had small numbers of cases and the percentages of all metabolic risk factors basically increased with a rise in VFA in both sexes, logistic regression analyses were performed without stratification by sex. The age-adjusted ORs for Mets components and the clustering according to VFA quartiles in all participants are shown in figure 2. Dose-dependent responses between VFA and all Mets components and the clustering were observed (all $\mathrm{p}$ for trend $<0.01$ ). The details of ORs and $95 \%$ CIs are shown in online supplementary table S1. The ORs for the Mets

Table 1 Characteristics of all participant variables

\begin{tabular}{|c|c|c|c|}
\hline & Men & Women & p Value \\
\hline $\mathrm{N}$ & 1674 & 1448 & \\
\hline Age, years & $51.2(10.2)$ & $49.8(9.7)$ & $<0.001$ \\
\hline Body Mass Index, $\mathrm{kg} / \mathrm{m}^{2}$ & $23.7(3.0)$ & $22.1(2.9)$ & $<0.001$ \\
\hline Visceral fat area, $\mathrm{cm}^{2}$ & $77.3(32.2)$ & 48.7 (24.9) & $<0.001$ \\
\hline Systolic blood pressure, $\mathrm{mm} \mathrm{Hg}$ & $119.0(15.2)$ & $113.3(16.7)$ & $<0.001$ \\
\hline Diastolic blood pressure, $\mathrm{mm} \mathrm{Hg}$ & $77.0(12.0)$ & $69.4(12.0)$ & $<0.001$ \\
\hline HDL-cholesterol, mmol/L & $1.51(0.37)$ & $1.86(0.40)$ & $<0.001$ \\
\hline Triglyceride, $\mathrm{mmol} / \mathrm{L}$ & $1.15(0.81-1.69)$ & $0.78(0.59-1.06)$ & $<0.001$ \\
\hline Fasting blood glucose, $\mathrm{mmol} / \mathrm{L}$ & $5.26(0.97)$ & $4.88(0.65)$ & $<0.001$ \\
\hline Smoking status (\%) (current, quit, never) & $25.7,36.0,38.4$ & $8.3,12.9,78.8$ & $<0.001$ \\
\hline Drinking status (\%) (current, quit, never) & $69.0,1.4,29.6$ & $41.9,1.0,57.1$ & $<0.001$ \\
\hline Exercise $(\%)(0,1-59, \geq 60 \mathrm{~min} /$ week $)$ & $42.0,28.8,29.2$ & $54.8,21.5,23.7$ & $<0.001$ \\
\hline Eating until full (\%) & 18.2 & 18.0 & 0.092 \\
\hline Eating quickly (\%) & 56.7 & 43.6 & $<0.001$ \\
\hline
\end{tabular}


Table 2 Percentages of participants having metabolic syndrome components according to BMI and VFA

\begin{tabular}{|c|c|c|c|c|c|c|c|c|}
\hline & \multicolumn{4}{|c|}{$\begin{array}{l}\text { Normal weight } \\
\left(\text { BMI } 18.5-22.9 \mathrm{~kg} / \mathrm{m}^{2}\right) \\
\text { VFA }\end{array}$} & \multicolumn{4}{|c|}{$\begin{array}{l}\text { Higher weight } \\
\left(B M I \geq 23.0 \mathrm{~kg} / \mathrm{m}^{2}\right) \\
\text { VFA }\end{array}$} \\
\hline & q1 & q2 & q3 & q4 & $\overline{\mathbf{Q 1}}$ & Q2 & Q3 & Q4 \\
\hline \multicolumn{9}{|l|}{ Men } \\
\hline $\mathrm{n}$ & 186 & 186 & 187 & 186 & 233 & 232 & 231 & 233 \\
\hline \multicolumn{9}{|l|}{ Case, \% } \\
\hline Clustering & 2.2 & 11.3 & 17.6 & 27.4 & 17.2 & 28.9 & 34.6 & 59.7 \\
\hline \multicolumn{9}{|l|}{ Mets components } \\
\hline High BP & 16.1 & 28.0 & 32.1 & 42.5 & 35.6 & 39.2 & 48.9 & 68.2 \\
\hline High FBG & 5.4 & 11.8 & 16.6 & 23.7 & 15.9 & 22.0 & 25.1 & 45.9 \\
\hline Low HDL-C & 1.6 & 1.6 & 2.7 & 5.4 & 4.3 & 7.8 & 11.7 & 12.0 \\
\hline High TG & 3.8 & 9.7 & 19.3 & 33.3 & 17.6 & 31.9 & 32.9 & 46.8 \\
\hline \multicolumn{9}{|l|}{ Women } \\
\hline $\mathrm{n}$ & 257 & 260 & 257 & 259 & 103 & 105 & 103 & 104 \\
\hline \multicolumn{9}{|l|}{ Case, \% } \\
\hline $\begin{array}{l}\text { Clustering } \\
\text { Mets components }\end{array}$ & 1.2 & 1.5 & 5.1 & 10.4 & 7.8 & 10.5 & 28.2 & 37.5 \\
\hline High BP & 12.1 & 16.5 & 15.2 & 29.0 & 15.5 & 30.5 & 56.3 & 59.6 \\
\hline High FBG & 3.1 & 2.7 & 5.1 & 6.6 & 3.9 & 8.6 & 16.5 & 27.9 \\
\hline Low HDL-C & 1.2 & 0.8 & 6.2 & 7.3 & 7.8 & 15.2 & 14.6 & 25.0 \\
\hline High TG & 0.4 & 1.9 & 3.5 & 8.5 & 2.9 & 7.6 & 20.4 & 27.9 \\
\hline $\begin{array}{l}\text { Quartiles for normal we } \\
\text { for higher weight are Q } \\
\text { Clustering is defined as } \\
\text { BMI, Body Mass Index; } \\
\text { syndrome; TG, triglycer }\end{array}$ & $\begin{array}{l}\text { ght are c } \\
-\mathrm{Q} 4 \text { (qu } \\
\text { having t } \\
\mathrm{BP}, \text { bloo }\end{array}$ & $\begin{array}{l}\text { Jartile p } \\
\text { nts are } \\
\text { bre risks } \\
\text { ire; FBC }\end{array}$ & $\begin{array}{l}\text { e 43.7, } \\
8.3 \text { and } \\
\text { BP, hig } \\
\text { g blood }\end{array}$ & $\begin{array}{l}\text { d } 71.6 \text { in } \\
\text { men, ar } \\
\text { low HDI } \\
\text { HDL-C }\end{array}$ & $\begin{array}{l}\text { and } 28.6, \\
\text {, } 67.0 \text { an } \\
\text { d high TG } \\
\text { density lip }\end{array}$ & $\begin{array}{l}\text { nd } 50.5 \text { i } \\
\text { in wome } \\
n \text { choles }\end{array}$ & $\begin{array}{l}\text { en, respe } \\
\text { ectively). } \\
\text { lets, mete }\end{array}$ & \\
\hline
\end{tabular}

Figure 2 Age-adjusted ORs for prevalence of each metabolic syndrome component and the clustering according to sex-specific and BMI-specific VFA quartiles in total participants. Clustering is defined as having two or more risks of high $\mathrm{BP}$, high FBG, low HDL-C and high TG. ORs, except for those with an asterisk, were significantly higher compared with the references $(p<0.05)$. *not significant $(p>0.05)$; BP, blood pressure; FBG, fasting blood glucose; HDL-C, high-density lipoprotein cholesterol; ref, reference; TG, triglycerides.

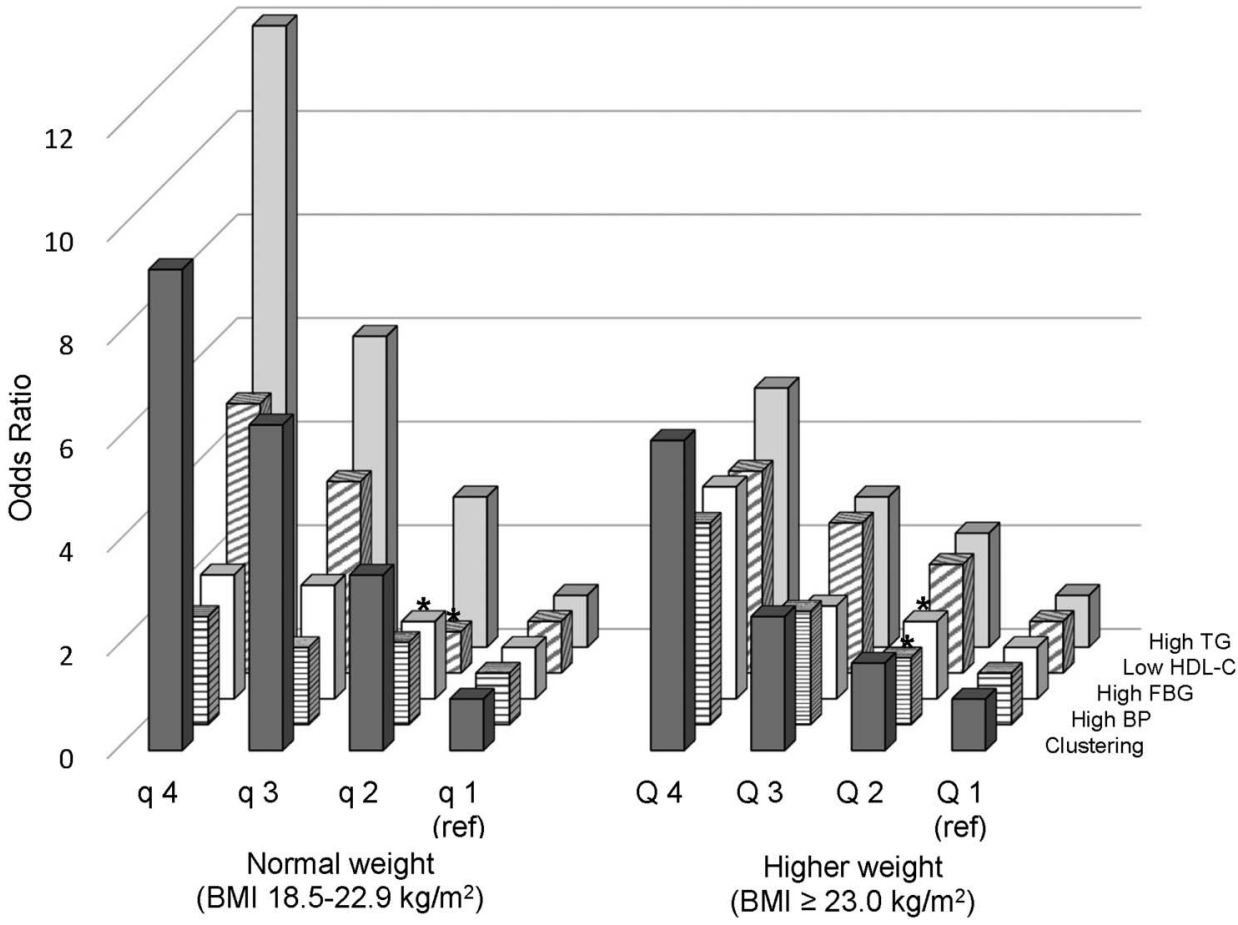

component clustering were significantly higher in the 2nd, 3rd and 4th quartile groups. The ORs (95\% CIs) were 3.42 (1.46 to 8.04 ), 6.29 (2.79 to 14.17 ) and 9.35 (4.22 to 20.68) in $\mathrm{q} 2$, q3 and $\mathrm{q} 4$ (BMI $18.5-22.9 \mathrm{~kg} / \mathrm{m}^{2}$ group), respectively, and 1.73 (1.16 to 2.58 ), 2.64 (1.79 to 3.88) and 6.00 (4.12 to 8.76) in Q2, Q3 and Q4 (BMI $\geq 23.0 \mathrm{~kg} / \mathrm{m}^{2}$ group), respectively. Although the 2nd quartile did not have a significantly high risk for all Mets components, the 3rd and 4th quartiles had a significantly high risk for all Mets components. The ORs of 
the 4th quartile for high BP, high FBG, low HDL-C and high TG were 2.12 (1.49 to 3.02), 2.42 (1.39 to 4.24), 5.23 (2.11 to 12.94 ) and 12.00 (5.69 to 25.31 ), respectively, in the normal weight group, and 3.90 (2.77 to 5.48 ), 4.13 (2.77 to 6.17 ), 3.93 (2.23 to 6.93 ) and 4.97 (3.37 to 7.35), respectively, in the higher weight group. These results did not change after excluding participants with liver or renal disease, thyroid disease, tumours or psychiatric disease (see online supplementary table S2 and figure S1). Additionally, because the definition of Mets based on the 2009 joint international statement does not include medical treatment of hypercholesterolaemia, the ORs for the clustering and low HDL-C adjusted for age and medical treatment of hypercholesterolaemia were estimated. As a result, the ORs did not change much. The ORs (95\% CIs) for the clustering were 3.31 (1.41 to 7.79 ), 6.11 (2.71 to 13.76 ) and 8.72 (3.93 to 19.35 ) in $\mathrm{q} 2$, q3 and q4, respectively, and 1.70 (1.14 to 2.55), 2.61 (1.77 to 3.85) and 5.94 (4.06 to 8.69) in Q2, Q3 and Q4, respectively. The ORs for low HDL-C were 0.82 (0.25 to 2.71$), 3.64$ (1.45 to 9.14$)$ and 5.06 (2.03 to 12.58) in q2, q3 and q4, respectively, and 2.09 (1.15 to 3.79), 2.84 (1.59 to 5.08) and 3.92 (2.22 to 6.90 ) in Q2, Q3 and Q4, respectively.

\section{VFA and Mets by age}

Of participants aged 30-64 years, 1620 were of normal weight and 1208 were of higher weight. Of those aged 65-74 years, 158 were of normal weight and 136 were of higher weight. The percentages and ORs of Mets in each age and BMI strata are shown in online supplementary table S3 and figure S2.

In the normal weight group, the ORs for the Mets component clustering were significantly higher in the 2nd, 3rd and 4th quartile groups aged 30-64 years and in the 3rd and 4th quartile groups aged 65-74 years. There was no significant interaction between age category and VFA quartile. In the higher weight group, the ORs for the Mets component clustering were significantly higher in the 2nd, 3rd and 4th quartile groups only among participants aged 30-64 years. Conversely, among participants aged 65-74 years, there was no significant association between VFA and Mets. The significant interaction between age category and VFA quartile was observed $(\mathrm{p}=0.038)$.

\section{Lifestyle factors and Mets}

Table 3 shows the estimated means of VFA according to lifestyle factors. Among normal weight participants, drinking, smoking and exercise habits were significantly associated with VFA in men, and eating quickly was significantly associated with VFA in women. As a result of multiple stepwise regression analysis, independent factors were the same among these lifestyle factors (see online supplementary table S4). As a result of multiple comparisons using the Bonferroni method for smoking habits, the significant difference was observed only between those who quit smoking and those who never smoked in normal weight men. Among higher weight participants, exercise habits and eating until full were significantly associated with VFA in men, and eating until full and eating quickly were significantly associated with VFA in women.

\section{DISCUSSION}

The present study demonstrated that even among normal weight individuals with BMIs $18.5-22.9 \mathrm{~kg} / \mathrm{m}^{2}$, dose-dependent responses were observed between VFA and risk of high BP, high FBG, low HDL-C, high TGs and Mets clustering, which are important targets for the prevention of cardiovascular diseases. Among lifestyle factors, currently drinking, poor exercise habit and eating quickly were associated with high VFA.

In a study of Japanese participants with a $\mathrm{BMI}<25.0 \mathrm{~kg} / \mathrm{m}^{2}$ reported by Hiuge-Shimizu et al, ${ }^{12}$ the mean number of Mets component (elevated BP, dyslipidaemia and abnormal glucose levels) increased with a rise in VFA, and the VFA value by which the mean number of risk factors exceeded one was $100 \mathrm{~cm}^{2}$. These authors suggest that VFA is positively associated with Mets component clustering, which is consistent with our study. However, in the present study, the VFA value that increased the risk was lower than $100 \mathrm{~cm}^{2}$ among normal weight individuals with a BMI $18.5-22.9 \mathrm{~kg} / \mathrm{m}^{2}$. Consequently, visceral fat accumulation $<100 \mathrm{~cm}^{2}$ may be an important factor for improvement. In addition, among normal weight individuals, the dose-dependent responses between VFA and Mets component clustering were observed in middle-aged individuals and the elderly in the present study. Further studies are needed to confirm the absence of age differences in a large population because the number of elderly subjects was small in the present study.

The present study also demonstrated that dosedependent responses were observed between VFA and all Mets components among normal weight individuals. At present, the degree of these risks has not been estimated in previous studies. ${ }^{7} 8$ Luo et $a l^{7}$ investigated Chinese participants with a $\mathrm{BMI}<25.0 \mathrm{~kg} / \mathrm{m}^{2}$ (average $21.7 \mathrm{~kg} / \mathrm{m}^{2}$ ), and reported that the mean levels of total cholesterol, TG, HDL-C and low-density lipoprotein cholesterol significantly increased with a rise in VFA. Miazgowski et $a l^{8}{ }^{8}$ investigated the association between visceral adipose tissue $\left(\mathrm{cm}^{3}\right)$ and $\mathrm{BP}$, blood glucose and lipid profiles in Caucasian women with an average BMI of $22.2 \mathrm{~kg} / \mathrm{m}^{2}$, and reported that visceral adipose tissue significantly correlated with levels of HDL-C and blood glucose, but not TG or BP. The associations between VFA and all Mets components were not consistent among the previous studies. There are several possible explanations for the conflicting results. These previous studies did not involve patients undergoing medical treatment. In the present study, the stronger associations between VFA and Mets might be observed because participants with medical treatment who might have high 
Table 3 Estimated means of VFA according to lifestyle factors by analysis of covariance

\begin{tabular}{|c|c|c|c|c|c|c|}
\hline & \multicolumn{3}{|c|}{$\begin{array}{l}\text { Normal weight } \\
\text { (BMl 18.5-22.9 kg/m²) }\end{array}$} & \multicolumn{3}{|c|}{$\begin{array}{l}\text { Higher weight } \\
\left(\mathrm{BMI} \geq 23.0 \mathrm{~kg} / \mathrm{m}^{2}\right)\end{array}$} \\
\hline & $\mathrm{n}$ & VFA & p Value & $\bar{n}$ & VFA & p Value \\
\hline \multicolumn{7}{|l|}{ Men } \\
\hline Drinking habits & & & 0.008 & & & 0.555 \\
\hline Current & 518 & 58.5 & & 637 & 93.9 & \\
\hline Quit + never & 227 & 54.1 & & 292 & 95.1 & \\
\hline Smoking habits & & & 0.030 & & & 0.094 \\
\hline Current & 191 & 57.1 & & 239 & 97.4 & \\
\hline Quit & 246 & 58.1 & \multirow[b]{2}{*}{0.035} & 356 & 91.9 & \\
\hline Never & 308 & 53.6 & & 334 & 94.2 & \\
\hline Exercise habits & & & 0.001 & & & $<0.001$ \\
\hline $0 \mathrm{~min} /$ week & 299 & 59.3 & \multirow{3}{*}{$\begin{array}{l}0.001 \\
0.030\end{array}$} & 404 & 101.1 & \multirow{3}{*}{$\longrightarrow \begin{array}{l}<0.001 \\
0.007\end{array}$} \\
\hline $1-59 \mathrm{~min} /$ week & 222 & 57.3 & & 260 & 93.8 & \\
\hline$\geq 60 \mathrm{~min} /$ week & 224 & 52.2 & & 265 & 88.6 & \\
\hline Eating until full & & & 0.550 & & & 0.001 \\
\hline No & 651 & 60.0 & & 719 & 90.5 & \\
\hline Yes & 94 & 55.6 & & 210 & 98.5 & \\
\hline Eating quickly & & & 0.783 & & & 0.177 \\
\hline No & 381 & 56.1 & & 344 & 93.1 & \\
\hline Yes & 364 & 56.5 & & 585 & 95.9 & \\
\hline \multicolumn{7}{|l|}{ Women } \\
\hline Drinking habits & & & 0.106 & & & 0.376 \\
\hline Current & 445 & 41.5 & & 161 & 74.7 & \\
\hline Quit + never & 588 & 39.9 & & 254 & 72.2 & \\
\hline Smoking habits & & & 0.769 & & & 0.351 \\
\hline Current & 85 & 41.6 & & 35 & 75.6 & \\
\hline Quit & 139 & 40.2 & & 48 & 74.9 & \\
\hline Never & 809 & 40.3 & & 332 & 70.0 & \\
\hline Exercise habits & & & 0.358 & & & 0.161 \\
\hline $0 \mathrm{~min} /$ week & 563 & 41.4 & & 230 & 77.1 & \\
\hline 1-59 $\mathrm{min} /$ week & 221 & 41.0 & & 91 & 71.5 & \\
\hline$\geq 60 \mathrm{~min} /$ week & 249 & 39.7 & & 94 & 71.9 & \\
\hline Eating until full & & & 0.823 & & & 0.047 \\
\hline No & 857 & 40.6 & & 330 & 70.2 & \\
\hline Yes & 176 & 40.8 & & 85 & 76.9 & \\
\hline Eating quickly & & & 0.009 & & & 0.025 \\
\hline No & 633 & 39.4 & & 184 & 70.3 & \\
\hline Yes & 400 & 42.0 & & 231 & 76.6 & \\
\hline
\end{tabular}

level of Mets components and VFA were included in the analyses. In addition, differences of distribution by sex, age or ethnic differences among studies might also have influenced the results.

In our study, normal weight men who consumed alcohol, had quit smoking and with poor exercise habits, and women who reported eating quickly had high VFA. For decreasing of VFA to improve Mets, the principal method is lifestyle modification. Although the associations between VFA and lifestyle have become an active area of research during the past decade, ${ }^{26-35}$ there is no study investigating these factors among normal weight individuals. Although there is no evidence among people with a BMI $18.5-22.9 \mathrm{~kg} / \mathrm{m}^{2}$, the present results appear to be accepted because alcohol consumption, quitting smoking, poor exercise habits and eating quickly have been reported to have an association with relatively high energy intake, weight gain and obesity. ${ }^{25}$ 36-38 Therefore, modifications for these lifestyle factors may contribute to improve Mets among normal weight individuals.

The present study has several limitations. First, because VFA was not measured by standard diagnostic methods, such as CT scan, we may have missed identifying VFA correctly. VFA estimation by the dual bioelectrical impedance analysis used in the present study can be influenced by body shape or body water distribution. ${ }^{39}$ However, the dual bioelectrical impedance analysis for measuring VFA is well correlated with that of $\mathrm{CT},{ }^{19}{ }^{20}$ and we used categorical information of VFA. 
Therefore, missing VFA classifications might occur less frequently. Second, the participants would have had relatively high health awareness because they voluntarily underwent comprehensive medical check-ups. According to the 2012 National Nutrition Survey in Japan, the percentages of those with a BMI $\geq 25.0 \mathrm{~kg} / \mathrm{m}^{2}$ were $29.1 \%$ in men and $19.4 \%$ in women. ${ }^{40}$ The participants in the present study had lower percentages, $27.0 \%$ in men and $12.3 \%$ in women. Therefore, application of the results in the present study to the general population should be carefully considered. Third, the present study had no detailed information including medical treatment and severity of diseases such as liver or renal disease, thyroid disease, tumours or psychiatric diseases which may influence VFA or Mets components. Although the analysis excluding participants who selfreported these diseases was conducted, the influence could not be completely evitable. Fourth, because of the small sample size of former drinkers, these participants were combined with the never drinkers. If the period from quitting alcohol consumption to the time of the health check-ups was short, the difference in the mean VFA might be underestimated. Fifth, because the present study was cross-sectional in design, causality could not be defined. If patients with metabolic risk factors made an effort to reduce their weight by lifestyle modifications, the risks of VFA would be underestimated. Finally, sex-specific risks for metabolic risk factors could not be estimated in the present study because of the small sample size. The risks by sex can be estimated in further studies with large samples.

In conclusions, dose-dependent responses were observed between VFA and risk of high BP, high FBG, high TG and low HDL-C and the clustering of these components among Japanese adults with a BMI $<23.0 \mathrm{~kg} / \mathrm{m}^{2}$. Further studies are needed to confirm the usefulness of VFA as informative for interventions to improve metabolic risk factors in normal weight people.

\author{
Author affiliations \\ ${ }^{1}$ Department of Hygiene and Public Health, Teikyo University School of \\ Medicine, Itabashi, Japan \\ ${ }^{2}$ Department of Preventive Medicine and Epidemiology Informatics, National \\ Cerebral and Cardiovascular Center, Suita, Japan \\ ${ }^{3}$ Department of Preventive Cardiology, National Cerebral and Cardiovascular \\ Center, Suita, Japan \\ ${ }^{4}$ Takeda Hospital Group, Kyoto, Japan \\ ${ }^{5}$ Department of Preventive Medicine and Public Health, Keio University, \\ Shinjuku, Japan
}

Acknowledgements We thank all the staff in the Health Check-up Center of the Takeda Hospital Group.

Contributors YT contributed to the conception of the work, performed statistical analysis and drafted the manuscript. YMN contributed to the conception of the work and revising the manuscript critically. IM contributed to the conception of the work and reviewed the manuscript. AH, MT, KN, MW contributed to the interpretation of the result and reviewed the manuscript. $\mathrm{TaO}$ and $\mathrm{ToO}$ contributed to the interpretation of the result and revising the manuscript critically. YM contributed to the design of the work and the interpretation of the result and reviewed the manuscript. All authors read and approved the final manuscript.
Funding This study was supported by a grant-in-aid for Young Scientists from the Japan Society for the Promotion of Science (15H06913), a grant-in-aid from the Ministry of Health, Labour and Welfare, Health and Labour Sciences research grants, Japan (Comprehensive Research on Cardiovascular Disease, Diabetes and Life-Style Related Diseases: H27Junkankitou (Seishuu)-Ippan-009), and an Intramural Research Fund (27-4-3) for Cardiovascular Diseases of National Cerebral and Cardiovascular Center.

Competing interests None declared.

Patient consent Obtained.

Ethics approval The study was approved by the Ethics Committee of the National Cerebral and Cardiovascular Center and Takeda Hospital Group (committee approval number: 1404).

Provenance and peer review Not commissioned; externally peer reviewed.

Data sharing statement No additional data are available.

Open Access This is an Open Access article distributed in accordance with the Creative Commons Attribution Non Commercial (CC BY-NC 4.0) license, which permits others to distribute, remix, adapt, build upon this work noncommercially, and license their derivative works on different terms, provided the original work is properly cited and the use is non-commercial. See: http:// creativecommons.org/licenses/by-nc/4.0/

\section{REFERENCES}

1. Gallagher D, Visser M, Sepúlveda D, et al. How useful is body mass index for comparison of body fatness across age, sex, and ethnic groups? Am J Epidemiol 1996;143:228-39.

2. WHO Expert Consultation. Appropriate body-mass index for Asian populations and its implications for policy and intervention strategies. Lancet 2004;363:157-63.

3. Romero-Corral A, Somers VK, Sierra-Johnson J, et al. Normal weight obesity: a risk factor for cardiometabolic dysregulation and cardiovascular mortality. Eur Heart J 2010;31:737-46.

4. Sahakyan KR, Somers VK, Rodriguez-Escudero JP, et al Normal-weight central obesity: implications for total and cardiovascular mortality. Ann Intern Med 2015;163:827-35.

5. Park HR, Shin SR, Han AL, et al. The correlation between the triglyceride to high density lipoprotein cholesterol ratio and computed tomography-measured visceral fat and cardiovascular disease risk factors in local adult Male subjects. Korean J Fam Med 2015;36:335-40.

6. Kang $\mathrm{SH}, \mathrm{Cho} \mathrm{KH}$, Park JW, et al. Association of visceral fat area with chronic kidney disease and metabolic syndrome risk in the general population: analysis using multi-frequency bioimpedance. Kidney Blood Press Res 2015:40:223-30.

7. Luo $\mathrm{Y}, \mathrm{Ma} X$, Shen $\mathrm{Y}$, et al. Positive relationship between serum low-density lipoprotein cholesterol levels and visceral fat in a Chinese non-diabetic population. PLOS ONE 2014;9:e112715.

8. Miazgowski T, Krzyzanowska-Świniarska B, Dziwura-Ogonowska J, et al. The associations between cardiometabolic risk factors and visceral fat measured by a new dual-energy X-ray absorptiometry-derived method in lean healthy Caucasian women. Endocrine 2014:47:500-5.

9. Unno M, Furusyo N, Mukae H, et al. The utility of visceral fat level by bioelectrical impedance analysis in the screening of metabolic syndrome-the results of the Kyushu and Okinawa Population Study (KOPS). J Atheroscler Thromb 2012;19:462-70.

10. Nakao YM, Miyawaki T, Yasuno S, et al. Intra-abdominal fat area is a predictor for new onset of individual components of metabolic syndrome: MEtabolic syndRome and abdominaL ObesiTy (MERLOT study). Proc Jpn Acad Ser B Phys Biol Sci 2012;88:454-61.

11. Nomura K, Eto M, Kojima T, et al. Visceral fat accumulation and metabolic risk factor clustering in older adults. J Am Geriatr Soc 2010;58:1658-63.

12. Hiuge-Shimizu A, Kishida K, Funahashi T, et al. Absolute value of visceral fat area measured on computed tomography scans and obesity-related cardiovascular risk factors in large-scale Japanese general population (the VACATION-J study). Ann Med 2012;44:82-92.

13. Foy CG, Hsu FC, Haffner SM, et al. Visceral fat and prevalence of hypertension among African Americans and Hispanic Americans: findings from the IRAS family study. Am J Hypertens 2008;21:910-16. 
14. Oka R, Kobayashi J, Yagi K, et al. Reassessment of the cutoff values of waist circumference and visceral fat area for identifying Japanese subjects at risk for the metabolic syndrome. Diabetes Res Clin Prac 2008;79:474-81.

15. Fox CS, Massaro JM, Hoffmann U, et al. Abdominal visceral and subcutaneous adipose tissue compartments: association with metabolic risk factors in the Framingham Heart Study. Circulation 2007;116:39-48

16. Guldiken S, Tuncbilek N, Okten OO, et al. Visceral fat thickness determined using ultrasonography is associated with anthropometric and clinical parameters of metabolic syndrome. Int $J$ Clin Pract 2006;60:1576-81.

17. Miyawaki T, Abe M, Yahata K, et al. Contribution of visceral fat accumulation to the risk factors for atherosclerosis in non-obese Japanese. Intern Med 2004;43:1138-44.

18. Kim SK, Kim HJ, Hur KY, et al. Visceral fat thickness measured by ultrasonography can estimate not only visceral obesity but also risks of cardiovascular and metabolic diseases. Am J Clin Nutr 2004;79:593-9.

19. Sakamaki K, Maejima $Y$, Tokita $Y$, et al. Impact of the Visceral Fat Area Measured by Dual Impedance Method on the Diagnostic Components of Metabolic Diseases in a Middle-aged Japanese Population. Intern Med 2016;55:1691-6.

20. Shiga T, Hamaguchi T, Oshima $Y$, et al. A new simple measurement system of visceral fat accumulation by bioelectrical impedance analysis. IFMBE Proc 2009;25:338-41.

21. Bouchi R, Minami I, Ohara N, et al. Impact of increased visceral adiposity with normal weight on the progression of arterial stiffness in Japanese patients with type 2 diabetes. BMJ Open Diabetes Res Care 2015;3:e000081.

22. Alberti KG, Eckel RH, Grundy SM, et al., International Diabetes Federation Task Force on Epidemiology and Prevention; National Heart, Lung, and Blood Institute; American Heart Association; World Heart Federation, et al. Harmonizing the metabolic syndrome: a joint interim statement of the International Diabetes Federation Task Force on Epidemiology and Prevention; National Heart, Lung, and Blood Institute; American Heart Association; World Heart Federation; International Atherosclerosis Society; and International Association for the Study of Obesity. Circulation 2009;120:1640-5.

23. Flegal KM, Kit BK, Graubard BI. Body mass index categories in observational studies of weight and risk of death. Am J Epidemiol 2014;180:288-96.

24. Ministry of Health, Labour and Welfare. Criteria of physical activity for health promotion. 2013. http://www.mhlw.go.jp/stf/houdou/ 2r9852000002xple-att/2r9852000002xppb.pdf (accessed $14 \mathrm{Apr}$ 2016).

25. Maruyama K, Sato S, Ohira T, et al. The joint impact on being overweight of self reported behaviours of eating quickly and eating until full: cross sectional survey. BMJ 2008;337:a2002.
26. Molenaar EA, Massaro JM, Jacques PF, et al. Association of lifestyle factors with abdominal subcutaneous and visceral adiposity: the Framingham Heart Study. Diabetes Care 2009;32: 505-10.

27. Onat A, Ayhan E, Hergenç G, et al. Smoking inhibits visceral fat accumulation in Turkish women: relation of visceral fat and body fat mass to atherogenic dyslipidemia, inflammatory markers, insulin resistance, and blood pressure. Metabolism 2009;58: 963-70.

28. Alexander KE, Ventura EE, Spruijt-Metz D, et al. Association of breakfast skipping with visceral fat and insulin indices in overweight Latino youth. Obesity (Silver Spring) 2009;17:1528-33.

29. Kim KH, Oh SW, Kwon $\mathrm{H}$, et al. Alcohol consumption and its relation to visceral and subcutaneous adipose tissues in healthy Male Koreans. Ann Nutr Metab 2012;60:52-61.

30. Matsushita Y, Nakagawa T, Yamamoto S, et al. Associations of smoking cessation with visceral fat area and prevalence of metabolic syndrome in men: the Hitachi health study. Obesity (Silver Spring) 2011;19:647-51.

31. Yun JE, Kimm H, Choi YJ, et al. Smoking is associated with abdominal obesity, not overall obesity, in men with type 2 diabetes. $J$ Prev Med Public Health 2012;45:316-22.

32. Lee $\mathrm{K}$, Lee $\mathrm{CM}$, Kwon $\mathrm{HT}$, et al. Associations of smoking and smoking cessation with CT-measured visceral obesity in 4656 Korean men. Prev Med 2012;55:183-7.

33. Vissers D, Hens W, Taeymans J, et al. The effect of exercise on visceral adipose tissue in overweight adults: a systematic review and meta-analysis. PLOS ONE 2013;8:e56415.

34. Nakanishi K, Nishida M, Ohama T, et al. Smoking associates with visceral fat accumulation especially in women. Circ $J$ 2014;78:1259-63.

35. Fukuda S, Hirata A, Nishizawa $H$, et al. Systemic arteriosclerosis and eating behavior in Japanese type 2 diabetic patients with visceral fat accumulation. Cardiovasc Diabetol 2015;14:8.

36. Suter PM, Häsler E, Vetter W. Effects of alcohol on energy metabolism and body weight regulation: is alcohol a risk factor for obesity? Nutr Rev 1997;55:157-71.

37. Westerterp-Plantenga MS, Verwegen CR. The appetizing effect of an apéritif in overweight and normal-weight humans. Am J Clin Nutr 1999;69:205-12.

38. Aubin HJ, Farley A, Lycett D, et al. Weight gain in smokers after quitting cigarettes: meta-analysis. BMJ 2012;345:e4439.

39. Kyle UG, Bosaeus I, De Lorenzo AD, et al., Composition of the ESPEN Working Group. Bioelectrical impedance analysis-part I: review of principles and methods. Clin Nutr 2004;23:1226-43.

40. Ministry of Health, Labour and Welfare. National Nutrition Survey. 2012. http://www.mhlw.go.jp/file/04-Houdouhappyou-10904750Kenkoukyoku-Gantaisakukenkouzoushinka/0000106403.pdf (accessed 14 Apr 2016). 